\title{
وسائل التواصل الإجتماعى وتأثيرها على المجتمع لممارسة الرياضة كأسلوب حياة صحى بدولة الكويت
}

* أر سعد محمد سند المطيري

مقدمة البحث: The Research Introduction

في ظل التطور الهائل في مجال المعلومات وتكنولوجيا الاتصال استطاعت التكنولوجيا إسقاط الحواجز والحدود بين الدول واحتلت الثورة المعلوماتية والتقنية الصدارة ومتلت نقلة نوعية في مجال التطور البشري وخاصة فى المجال الرياضى ، ومن انتاجات هذه الثورة الانترنت التي

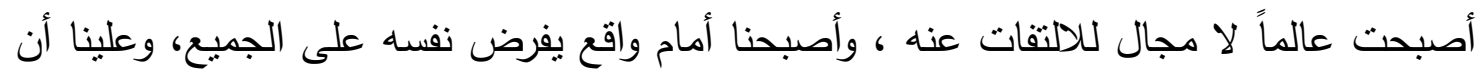
نعترف أن هناك وسائل متاحة نسهم فى توفر المعلومات عن الرياضة ومكوناتها وكيفية أداء تدريباتها بسهولة ويسر.

وظهرت في الاونة الاخيرة الكثير من وسائل التواصل الحديثة نتيجة الثورة التكنولوجية، والتي

بدورها تقرب المسافات بين الافراد ومنها ، شبكة الانترنت Online وتطبيقاتها، منل السناب شات ، الفيس بوك، وتويتر ، و اليوتيوب ، ومواقع الارشة و الانترنت وهى عبارة عن شبكة عالمية ضخمة تربط بين الملايين من أجهزة الحاسب الآلي الموجودة في مناطق مختلفة حول العالم. (مصطفى رضا وليا عبد الوهاب وآخرون : 17-18) وقد بدأت وسائل التواصل الاجتماعي في الظهور في منتصف التسعينيات حيث أنثئ موقع

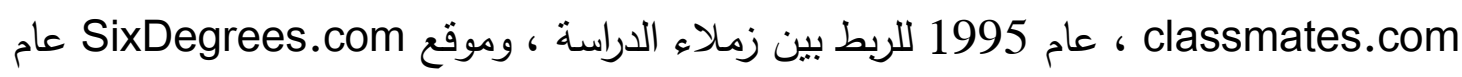
1997الذي ركز على الروابط المباشرة بين الأشخاص، وظهرت تلاك المواقع الملفات الثخصية

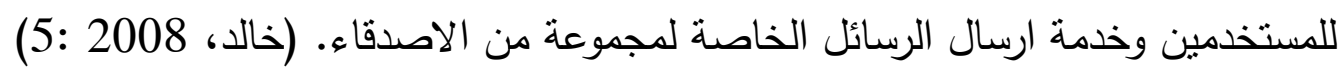
وأظهرت دراسة (منصور، 2012) إرتفاع عدد مستخدمي شبكات التواصل الإجتماعي الرئيسية علي شبكة الإنترنت (فيس بوك ، تويتر ، لينكد إن) ليسجل مؤخراً ما مجموعه ، 70.3

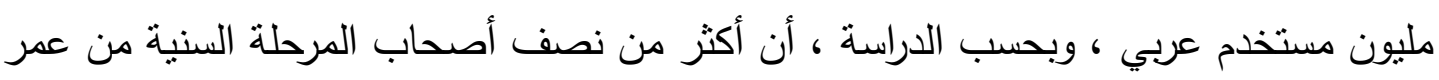
(12-17) لهم صفحات إلكترونية ، ومقاطع فيديو ، ومدونات إلكترونية ، ومواقع علي شبكات

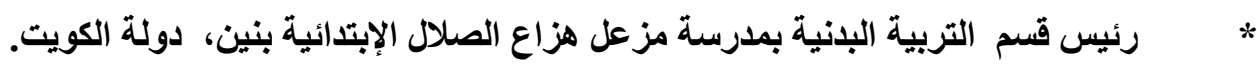


التواصل الإجتماعي ، خاصة بهم ، ويصل عدد الساعات التي يقضيها فئة عمر (12-17) أمام الأجهزة الإكترونية ومواقع النتاصل إلي ثماني ساعات في اليوم ـ (منصور 2012) أهم وسائل التواصل الاجتماعي:

من الثبكات الاجتماعية الموجودة على الثبكة، ولا يدل هذا الاختيار على الأفضلية بقدر ما يشير إلى سعة الانتتار ، والتداول، وخاصة على المستوى العربي، ومن بين تلك الثبكات ما يلي: 1. (الفيس بوك::Face book)

يعتبر موقع " الفيس بوك " واحدا من أهم مواقع التتبيك الاجتماعي، وهو لا يمنل منتدى اجتماعيا فقط، وإنما أصبح قاعدة تكنولوجية سهلة بإمكان أب شخص أن يفعل بواسطتها ما يشاء

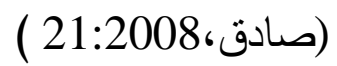

وينكون الموقع من مجموعة من الثبكات تتألف من أعضاء، وتصنف المجموعات على أساس الأقليم ومكان العمل والجامعة والمدرسة، وبإمكان المشترك الجديد أن يختار أحد تلك التصنيفات، ثم يبدأ بالتصفح واختيار مجموعة للاشتراك فيها ـ ( الاليمي، 2011 : 1 )

2.

هو موقع شبكات اجتماعية يقدم خدمة تدوين مصغّر، والتي تسمح لمستخدميه بإرسال تحديثات Tweets عن حالتهم بحد أقصى 140 حرف للرسالة الواحدة ـ (منصور 88: 2012 ) 3. جوجل أو جوجل بلس(Google, Google+) هي شبكة اجتماعية، تم إنثاؤها بواسطة شركة ( جوجل)، ( جوجل بلس ) .

(Weblogs):

ظهرت المدونات في عام (1997) على يد ( John Barger ) إلا أنّ انتشارها على نطاق واسع لم يبدأ إلا بعد عام (1999) ، وهو موقع شخصي على شبكة الإنترنت، يدون فيه آرأه ومواقفه

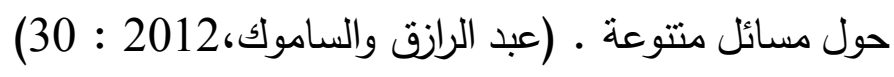
: Snapchat 5ناب شات

"هو تطبيق تواصل اجتماعي لتسجيل وبث ومشاركة الرسائل المصورة وضعها إيفان شبيغل وبوبي ميرفي، ثم طلبة جامعة ستانفورد. عن طريق التطبيق، يمكن للمستخدمين النقاط 
الصور ، وتسجيل الفيديوهات، وإضافة نص ورسومات، وإرسالها إلى قائمة التحكم من المتلقين. ومن المعروف أن هذه الصور ومقاطع الفيديو المرسلة على أنها "لقطات ."

مشكلة البحث: Research problem

يتتاول نموذج روز نجرين مجموعة العوامل التي تتتكل منها نظرية الاستخدامات والإثباعات الاجتماعية والبيولوجية والنفسية الموجودة لدي الإنسان حيث تثفاعل هذه الحاجات مع لع الإطار المجتمي وخصائص الفرد ، وهنا يلجأ الفرد إلى الوسيلة الإعلامية التي يري في مضمونها حلا لمشكلاته واشباعاً لحاجاته ـ ( جرار 2012 : 125) وان مواقع التواصل الاجتماعي في ظل النظرية تقوم بدور الملبي لحاجات الجمهور النفسية

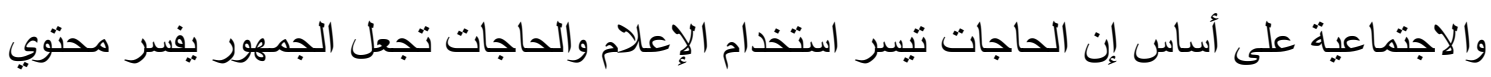
الإعلام بطريقة مختلفة .(الدليمي 2011 : 13) وتتوفر بوسائل التواصل الإجتماعي كثير من الصفحات التى تحتوى على الوصف

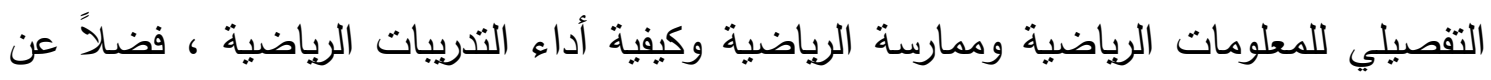
المحتوى التوضيحى لكيفية أداء التمارين الرياضية وتكراراتها ومدة إستمراريتها، والمعلومات حول الممارسات والعادات الصحية السليمة بطريقة سهلة تُكن المستخدم من الإستفادة منها. لذا إرتأى الباحث ضرورة التعرف على وسائل التواصل الإجتماعى وتأثيرها على المجتمع لممارسة الرياضة كأسلوب حباة صحى بدولة الكويت . هدف البحث: Research Objective يهدف البحث إلى التعرف علي : - وسائل التواصل الإجتماعى وتأثثرها على المجتمع لممارسة الرياضة كأسلوب حياة صحى بدولة الكويت .

\section{تساؤلات البحث: Research Question}

- ما وسائل التواصل الإجتماعى ؟ - ما تأثيرها على المجتمع لممارسة الرياضة كأسلوب حياة صحى بدولة الكويت؟ 


\section{مصطلحات البحث: Research Terms التواصل اصطلاحاً:}

للتواصل عدة تعريفات نختار منها "استمرار العلاقة المتينة بين طرفي العلاقة المشاركين

فيها". (عصام سليمان موسي : 23 (عنم)

ومنها "علاقة بين فردين على الأقل كل منهما يمثل ذات نشيطة". (محمود حسن

إسماعيل:30 (30)

ولذا يعتبر التواصل " بناء علاقة بين طرفين مما يحقق المنفعة المتبادلة بينهم".

اذن فوسائل النواصل الحديثة هي : تبادل المعلومات و الرسائل اللغوية وغير اللغوية سواء

أكان هذا التبادل قصديا أم غير قصدي، بين الأفراد والجماعات .وبالتالي لا يقتصر التواصل على ما لها

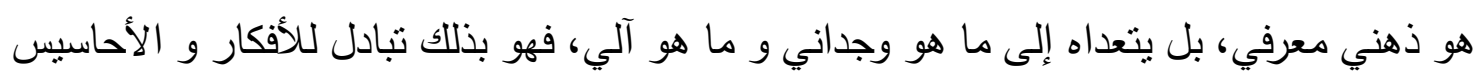
والرسائل التي قد تقهم و قد لا تفهم بنفس الطريقة من طرف كل الأفراد المتواجدين في و ضعية تواصلية.

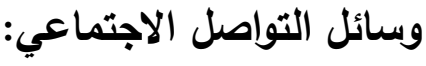
منظومة من الثبكات الإلكترونية، التي تسمح للمشترك فيها بإنشاء مواقع خاصة بهم، ومن ثم ربطه من خلال نظام اجتماعي الكتروني مع أعضاء آخرين لليهم الاهتمامات والهوايات نفسها، أو مع أصدقاء الجامعة أو الثانوية ـ (راضي , 2003 ,ص 23) الاراسات المرتبطة:

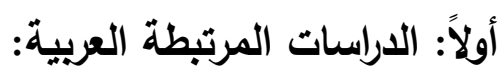
1- دراسة شكري عبد الحميد حماد (2014م) بعنوان" الوسائل التواصل الإجتماعي وأثرها علي المجتمع ، نظرة شرعية إجتماعية قانونية" ، الهذف من الدراسة : التعرف على الرعاية النفسية للاعبين بعد المنافسة ومستوى طموحهم الرياضي ، توصلت الدراسة إلي توضيح المطلب

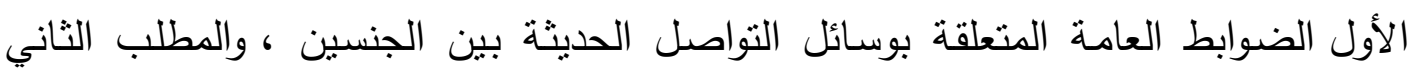
الضوابط الثرعية الخاصة بوسائل التواصل الحديثة مقسمة إلى عدة اعتبارات. 
2- دراسة أسامة غازي المدني (2014م) بعنوان" دور شبكات التواصل الاجتماعي في تشكيل

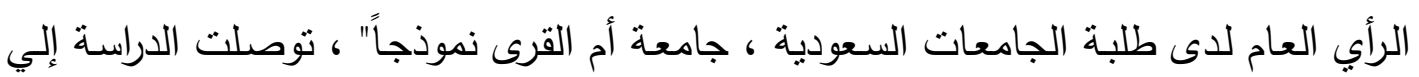
وجود فروق ذات دلالة إحصائية بين متوسطات درجات المبحوثين على مقياس دور شبكات التواصل الاجتماعي فى تثكيل الرأي العام لاى الطاب تبعاً لاختلاف مستويات استخدام شبكات التواصل الاجتماعي المختلفة . 3- دراسة رشا أديب محمد عوض (2014م) بعنوان" آثار استخدام مواقع التواصل الاجتماعي على التحصيل الدرارسي للأبناء في محافظة طولكرم من وجهة نظر ربات البيوت " ، نوصلت الدراسة إلي إن لمواقع التواصل الاجتماعي تأثثراً سلبيا على التحصيل الدراسي للأبناء في لني

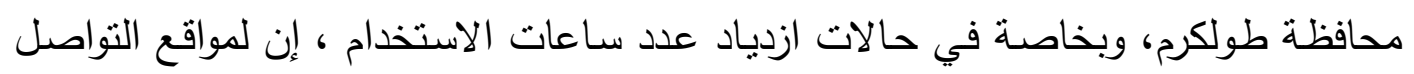

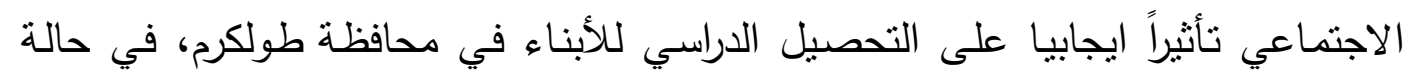

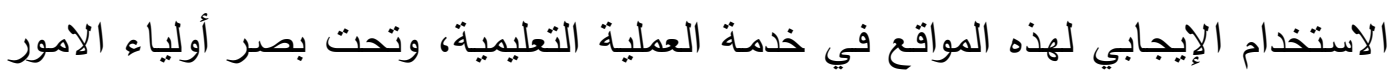
وتوجيه8. 4- دراسة أحمد يونس محمد حمودة (2013م) بعنوان" دور شبكات التواصل الاجتماعي في تتمية مشاركة الثباب الفلسطيني في القضايا المجتمية" ، توصلت الدراسة إلي جميع المبحوثين يستخدمون الثبكات الاجتماعية إذ جاءت نسبة من يستخدمونها بشكل دائم بنسبة 69.1 \% ، وبلغت الذين يستخدمونها أحياناً بنسبة 3.9 \% ، كما أن المبحوثين يتابعون لقضايا المجتمعية على شبكات التواصل الاجتماعي بنسبة كبيرة بلغت 99.3 \% ، إذ جاءت نسبة من أجابوا بنعم 82.3 \% ، وأحياناً بنسبة 17.1\% ، في حين أن 0.7 \% أجابوا بعدم

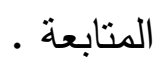
5- دراسة وسـام طايل البشابشـة (2013م) بعنوان "دوافع استخدام طلبة الجامعات الأردنية لمواقع

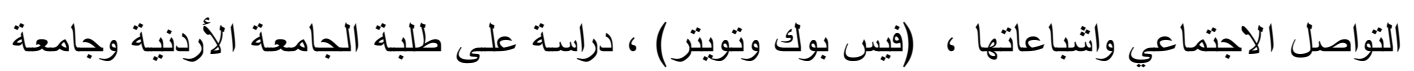

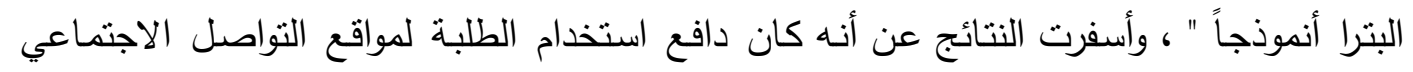
بغرض التواصل مع الأقارب والأهل هو الأكبر بنسبة (89.174\%) ، و و تلاه دافع الترفية والتسلية

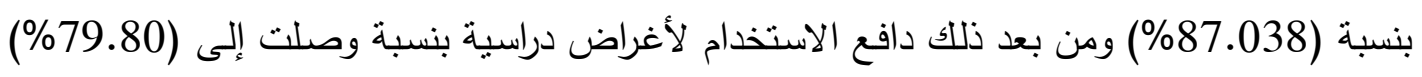

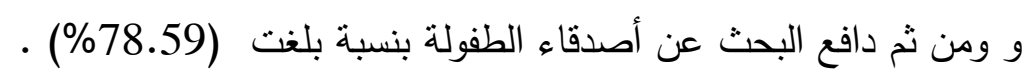


6- دراسة مريم نريمان نومار (2012م) بعنوان "استخدام مواقع الثبكات الاجتماعية وتأثيره في

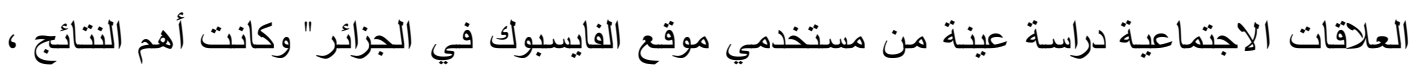
هنالك فروق ذات دلالة إحصائية بين استخدام الذكور والإناث، وتبين أيضا أن المبحوثين الأكبر سناً

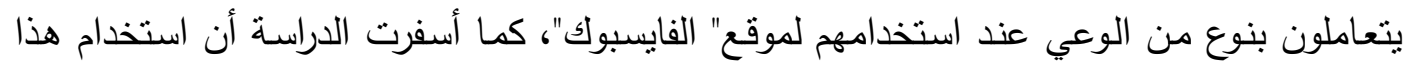
الموقع يؤثر في الاتصال الثخصي وجها لوجه، وفي تفاعل المستخدين مع أسرهم وأقاربهم وأصدقائهم كما يؤدي إلي الانسحاب الملحوظ للفرد من التناعل الاجتماعي.

ثانياً: الاراسات المرتبطة الأجنبية:

7- دراسة . Iordache, D. D. Lamanauskas, V) هدفت الدراسة إلى استكثاف

استخدام مواقع شبكات التواصل الاجتماعي في تثكيل الدفاهيم السياسية والرأي العام لثباب الجامعات في رومانيا، وتم التوصل إلى النتائج التالية، أظهرت التحليلات أن أكثر شبكات التواصل الاجنماعي التي يحرص طاب الجامعات الرومانية على استخدامها هي الفيس بوك ثم اليوتيوب ، ظهرت علاقة ارتباط موجبة بين استخدام مواقع التواصل الاجتماعي والمشاركة السياسية وتوجيه الرأي العام الطلبةي نحو القضايا في رومانيا.

إجراءات البحث: Procedures of The Research

منهج البحث: The Research Methodology

اعتمدت هذه الدراسة في سبيل الوصول إلى أهدافها والإجابة على أسئلتها الدنهج الوصفي الارتباطي ولم يقف المنهج الوصفي عند جمع المعلومات لوصف الظاهزة وإنما كما يشير يتعدى ذللك إلى توضيح العلاقة ومقدارها واستتناج الأسباب الكامنة وراء سلوك معين من معطيات سابقة . والبحث المسحي الارتباطي هو الذي يسعى لدراسة العلاقات الارتباطية بين المتغيرات المختلفة، حيث إن الباحث حاول معرفة وسائل التواصل الإجتماعى وتأثثرها على المجتمع لممارسة الرياضة كأسلوب حياة صحى بدولة الكويت ، حيث طبق الباحث في دراسته المنهج الوصفي الارتباطي

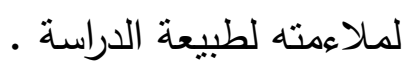

\section{مجتمع وعينة البحث: Research community \& Sample}

إثتمل مجتمع البحث على الثباب خريجى الجامعة بدولة الكويت ، وتم اختيار (347) 
شاب وشابة فى المرحلة العمرية من 21-27 سنة ويمثلوا العينة الأساسية.

(1) (1) - 20)

توصيف مجتمع وعينة البحث

\begin{tabular}{|c|c|c|}
\hline النسبة" المئوية & $\varepsilon$ & المجتمع \\
\hline$\% 100$ & 436 & مجتمع الأصل \\
\hline$\% 48.1$ & 357 & مجتمع البحث \\
\hline$\% 45.8$ & 347 & العينة الأساسية \\
\hline$\% 2.29$ & 10 & العينة الاستطلاعية \\
\hline
\end{tabular}

يوضح جدول رقم (1) توصيف مجتمع وعينة البحث

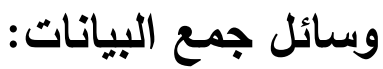

- - استمارة الاستبيان إعداد الباحث:

لتحقيق أهداف هذا البحث قام الباحث بإعداد أداة البحث ، وهى (إستنيان وسائل التواصل الإجتماعى وتأثيرها على المجتمع لممارسة الرياضة كأسلوب حياة صحى بدولة الكويت) ، حيث تمت مراجعة الأدب المرتبط والدراسات المرتبطة المتعلقة بالموضوع، وبناء على ذلك تم بناء

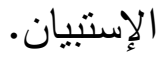

\section{-}

قام الباحث بالإطلاع على المراجع العلمية المتخصصة والدراسات المرتبطة فى مجال علم النفس الرياضي واستطلاع رأى الخبراء حيث قام الباحث بتحديد محرين وتم وضعهم في استمارة استطلاع رأى الخبراء حول هذه المحاور (مرفق 2) لتحديد محاور وسائل التواصل الإجتماعى وتأثيرها على المجتمع لممارسة الرياضة كأسلوب حياة صحى بدولة الكويت ، والذى حدد لله مقياس ثلاثى متدرج لتحديد درجة موافقة أفراد عينة هذا البحث على القيم المتوفرة، حيث كانت درجة تقدير الإستجابة (نعم، محايد، لا ).

قام الباحث بعرض هذه المحاور على عدد (5) من السادة الخبراء المتخصصين في علم

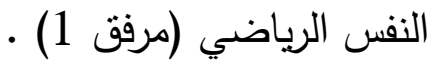


ويوضح جدول رقم (2) المتوسطات والإنحرافات المعيارية لدرجات آراء الخبراء حول

محاور استبيان وسائل التواصل الإجتماعى وتأثيرها على المتمع لممارسة الرياضة كأسلوب حياة صحى بدولة الكويت.

جدول (2) جأ (2)

المتوسطات والإنحرافات المعيارية لارجات آراء الخبراء حول محاور استبيان وسائل التواصل

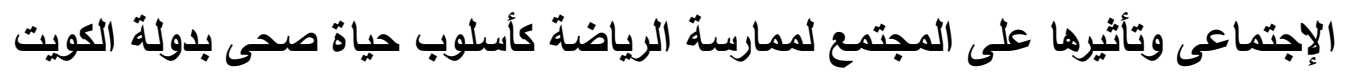

\begin{tabular}{|c|c|c|c|c|}
\hline الترتيب & المعيارى & الحسابي & المحور & r \\
\hline 1 & 1,32 & 5.60 & وسائل التواصل الإجتماعى & 1 \\
\hline 2 & 1,32 & 5.57 & تلأثير وسائل التواصل الإجتماعى على المجتمع الرياضعة كأسلوب حياة صحى بدولة & 2 \\
\hline
\end{tabular}

يوضح جدول رقم (2) المنوسطات والإنحرافات المعيارية لارجات آراء الخبراء حول محاور

استنيان وسائل التواصل الإجتماعى وتأثثرها على المجتمع لممارسة الرياضة كأسلوب حياة صحى بدولة الكويت.

جدول (3)

النسبة المئوية لآراء الخبراء فى كل عبارة من عبارات الإستبيان

$(10=\dot{0})$

\begin{tabular}{|c|c|c|c|c|c|}
\hline \multicolumn{3}{|c|}{ المحور الثناني } & \multicolumn{2}{|c|}{ المحور الاول } & \multirow[b]{2}{*}{ رقم العبارة } \\
\hline النسبة المئوياة & الموأفقين & رقم العبارة & المئويبية & الموافقيدن & \\
\hline$\% 80$ & 8 & 5 & $\% 100$ & 10 & 1 \\
\hline$\% 80$ & 8 & 6 & $\% 90$ & 9 & 2 \\
\hline$\% 90$ & 9 & 7 & $\% 80$ & 8 & 3 \\
\hline$\% 100$ & 10 & 8 & $\% 90$ & 9 & 4 \\
\hline$\% 100$ & 10 & 9 & & & \\
\hline$\% 90$ & 9 & 10 & & & \\
\hline$\% 80$ & 8 & 11 & & & \\
\hline$\% 80$ & 8 & 12 & & & \\
\hline$\% 90$ & 9 & 13 & & & \\
\hline$\% 90$ & 9 & 14 & & & \\
\hline$\% 80$ & 8 & 15 & & & \\
\hline$\% 90$ & 9 & 16 & & & \\
\hline$\% 80$ & 8 & 17 & & & \\
\hline$\% 100$ & 10 & 19 & & & \\
\hline
\end{tabular}


يوضح جدول رقم (3) نسبة آراء الخبراء في كل عبارة من عبارات استبيان (وسائل التواصل الإجتماعى وتأثيرها على المجتمع لممارسة الرياضة كأسلوب حياة صحى بدولة الكويت)

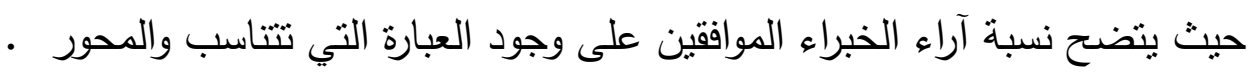

الدراسة الاستطلاعية:

قام الباحث بإجراء الدراسة الاستطلاعية خلا الفترة من يوم الخميس الموافق 2019/9/5م إلي يوم الخميس الموافق 2019/9/20م حيث أجري الباحث النطبيق لإيجاد الأتساق وقام بأجراء التطبيق الثانى لإيجاد الثبات بعد اعتبار تطبيق الأتساق الداخلى تطبيق أول

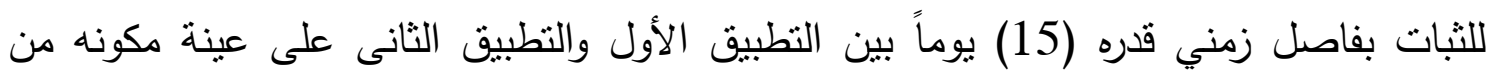
(10) شاب وشابة وذللك لإيجاد المعاملات العلمية للإستنيان من صدق وثبات.

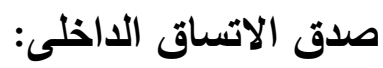
يُقصد بصدق الإتساق الداخلى فوة الإرتباط بين درجات كل فقرة من فقرات الإستيان والدرجة الكلية للمحور الى تتنمى إليه وكذلك إرتباط كل محور من محاور الإستبيان بالدرجة الكلية للإستبيان.

\section{جدول (4)}

\begin{tabular}{|c|c|c|c|}
\hline \multicolumn{2}{|c|}{ المحور الثانى } & \multicolumn{2}{|c|}{ المحور الأول } \\
\hline معامل الإرتباط & رقم العبارة & معامل الإرتباط & رقم العبارة \\
\hline${ }^{*} 0.692$ & 5 & *0.689 & 1 \\
\hline *0.790 & 6 & ${ }^{*} 0.401$ & 2 \\
\hline *0.567 & 7 & *0.566 & 3 \\
\hline${ }^{*} 0.723$ & 8 & ${ }^{*} 0.472$ & 4 \\
\hline *0.818 & 9 & & \\
\hline *0.471 & 10 & & \\
\hline *0.603 & 11 & & \\
\hline$* 0.573$ & 12 & & \\
\hline *0.538 & 13 & & \\
\hline *0.719 & 14 & & \\
\hline$* 0.673$ & 15 & & \\
\hline *0.825 & 16 & & \\
\hline *0.753 & 17 & & \\
\hline *0.625 & 19 & & \\
\hline
\end{tabular}

* قيمة (ر) الجدولية عند مستوى معنوية (0.05) = 0.361. 
يوضح جدول رقم (4) صدق الاتساق الداخلي لعبارات الاستبيان حيث يتضح وجود علاقة

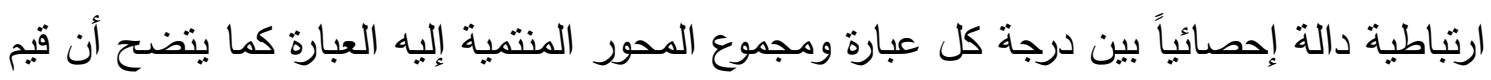
معاملات الارتباط تفوق حد الدلالة الإحصائية عند مستوى (0.05) وهذا يكون مؤشر لصدق بناء الاتساق الداخلي للاستنيان.

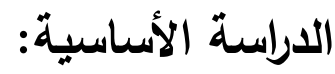

قام الباحث بتطبيق الدراسة الأساسية لأخذ آراء عينة البحث في عبارات الإستيان، ثم معالجتها إحصائياً في الفترة من السبت 2019/9/22م حتي الخميس 2019/10/7م. المعالجة الإحصائية المستخدمة فى البحث: لتحقيق أهداف البحث نم إستخدام الأساليب الإحصائية المناسبة بإستخدام الحزمة الإحصائية SPSS. عرض ومناقثة النتائج :

أولاً :عرض نتائج تساؤل البحث الأول وتفسيرها ومناقثتها: وينص هذا التساؤل على مايلى :- ما وسائل التواصل الإجتماعى ؟ وللإجابة عن هذا التساؤل قام الباحث بتحليل إستجابات عينة البحث علي أسئلة الإستبيان. 1. ما وسائل التواصل الإجتماعي التي تقبل علي إستخدامها؟

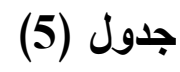
وسائل التواصل الإجتماعي التي تقبل علي إستخذامها

\begin{tabular}{|c|c|c|}
\hline \multicolumn{2}{|c|}{ عينة البحث } & \multirow{2}{*}{ وسيلة } \\
\hline$\%$ & ك & \\
\hline 37,4 & 130 & (Face book):الفيس بوك \\
\hline 12,3 & 43 & (Twitter):تويتر \\
\hline 4,3 & 15 & جوجل أو جوجل بلس \\
\hline 3.4 & 12 & المدونات:(Weblogs) \\
\hline 42.3 & 147 & سناب شات Snapchat \\
\hline 100 & 347 & الإجمالـي \\
\hline
\end{tabular}


تثنير النتائج التقصيلية للجدول السابق أن أكثر وسائل التواصل الإجتماعي إستخداماً جاءت بالترتيب التالي: سناب شات ( Snapchat) بنسبة 42.4\% الفيس بوك Face) book) بنسبة 65\%، ثم موقع نويتر (Twitter) بنسبة 21.5\% ، موقع جوجل أو جوجل بلس بلس

$$
\begin{aligned}
& \text { بنسبة 7.5\% ، موقع المدونات (Weblogs) بنسبة } 6 \text { \% من الإستخدام. } \\
& \text { 2. هل تستخدم وسائل التواصل الإجتماعي ؟ }
\end{aligned}
$$

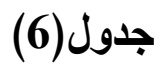

\begin{tabular}{|c|c|c|}
\hline \multicolumn{2}{|c|}{ عينة البحث } & \multirow{2}{*}{ مدي الإستخذام } \\
\hline$\%$ & ك & \\
\hline 92,2 & 320 & نعم \\
\hline 7.7 & 27 & ע \\
\hline 100 & 347 & الإجمالى \\
\hline
\end{tabular}

مدي إستخدام وسائل التواصل الإجتماعي

تثنير النتائج التفصيلية للجدول السابق أن نسبة إستخدام وسائل التواصل الإجتماعي من إجمإلى مفردات عينة الدراسة بلغت 92.2\% ، وبلغت نسبة من لا يستخدم وسائل التواصل الإجتماعي من إجمإلى مفردات عينة الدراسة 7.7\%

3. هل تستخدم وسائل التواصل الإجتماعي لمساعدتك علي ممارسة الرياضة؟

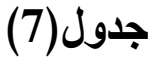

\begin{tabular}{|c|c|c|}
\hline \multicolumn{2}{|c|}{ عينة البحث } & \multirow{2}{*}{ لدي الإستخدام } \\
\hline$\%$ & ك & \\
\hline 88.18 & 306 & نعم \\
\hline 11.82 & 41 & $\gamma$ \\
\hline 100 & 347 & الإجمالي \\
\hline
\end{tabular}

مدي إستخدام وسائل التواصل الإجتماعي للمساعدة علي ممارسة الرياضة

تشير النتائج التقصيلية للجدول السابق أن نسبة من بستخدم وسائل التواصل الإجتماعي للمساعدة علي ممارسة الرياضة من إجمإلى مفردات عينة الدراسة بلغت 88.18\% ، بينما بلغت 
نسبة من لا يستخدم وسائل التواصل الإجتماعي للمساعدة علي ممارسة الرياضة مطلقاً من إجمإلى مفردات عينة الدراسة بلغت 11.82\%. 4. ما معدل استخدامك لها ؟

جدول(8)

معدل إستخدام عينة البحث لوسائل التواصل الإجتماعي

\begin{tabular}{|c|c|c|}
\hline \multicolumn{2}{|c|}{ عينة البحث } & \multirow{2}{*}{ معدل الإستخدام } \\
\hline$\%$ & ك & \\
\hline 94.3 & 327 & مرة واحدة يومياً \\
\hline 3.7 & 13 & مـرتان في الأسبوع \\
\hline 2 & 7 & ثُلاث مرات في الأسبوع \\
\hline 100 & 347 & الإجمالـي \\
\hline
\end{tabular}

تشير النتائج التقصيلية للجدول السابق أن نسبة من يستخدم وسائل التواصل الإجتماعي

مرة واحدة يومياً بلغت 94.3\% من إجمإلى مفردات من يستخدم وسائل التواصل الإجتماعي من إجمإلى عينة الدراسة ، وجاءت نسبة من يستخدم وسائل التواصل الإجتماعي بمعدل مرتان في الأسبوع 3.7\% من إجمإلى عينة الدراسة ، بينما جاءت نسبة من يستخدم وسائل التواصل الإجتماعي ثلاث مرات في الأسبوع 2\% من إجمإلى عينة الدراسة .

5. في أي الأوقات تستخدم وسائل التواصل الإجتماعي ؟ (يمكنك اختيار أكثر من بديل):

جدول(9)

أوقات إستخدام وسائل التواصل الإجتماعي

\begin{tabular}{|c|c|c|}
\hline \multicolumn{2}{|c|}{ عينة البحث } & \multirow{2}{*}{ وقت الإستخدام } \\
\hline$\%$ & ك5 & \\
\hline 74.06 & 257 & بداية اليوم \\
\hline 15.56 & 54 & نهاية اليوم \\
\hline 6.65 & 23 & في منتصف اليوم \\
\hline 3.74 & 13 & في وقت الفراغ \\
\hline 100 & 347 & الإجمالـي \\
\hline
\end{tabular}


تثير النتائج التفصيلية للجدول السابق أن نسبة من يستخدم وسائل التواصل الإجتماعي في بداية اليوم الدراسي بلغت 74.06\% من إجمالىى مفردات من يستخدم وسائل التواصل الإجتماعي من إجمإلى عينة الدراسة ، وجاءت نسبة من يستخدم وسائل التواصل الإجتماعي بمعدل نهاية اليوم 15.56\% من إجمإلى عينة الدراسة ، بينما جاءت نسبة من بيتخدم وسائل التواصل الإجتماعي في منتصف اليوم 6.65 ، بينما جاءت نسبة من يستخدم وسائل التواصل الإجتماعي في وقت الفراغ 3.74\% من إجمإلى عينة الدراسة .

6. ما الفترة الزمنية التي تستغرقها في إستخدامك وسائل التواصل الإجتماعي ؟ جدول(10)

أوقات إستخدام وسائل التواصل الإجتماعي

\begin{tabular}{|c|c|c|}
\hline \multicolumn{2}{|c|}{ عينة البحث } & \multirow{2}{*}{ وقت الإستخدام } \\
\hline$\%$ & 5 & \\
\hline 10.9 & 38 & أقل من ساعة \\
\hline 6.62 & 23 & سـاعـة \\
\hline 10.03 & 36 & ساعتيـن \\
\hline 70.60 & 245 & ثلاث ساعات \\
\hline 1.40 & 5 & أكثر من ثلاث ساعات \\
\hline 100 & 347 & الإجمالـي \\
\hline
\end{tabular}

تثنير النتائج التفيلية للجدول السابق أن نسبة وقت من يستخدم وسائل التواصل الإجتماعي لأقل من ساعة يومياً بلغت 10.9\% من إجمإلى عينة الدراسة ، وجاءت نسبة من يستخدم وسائل التواصل الإجتماعي مدة ساعة يوميا 6.62\% من إجمالِى عينة الدراسة ، بينما جاءت نسبة من يستخدم وسائل التواصل الإجتماعي لمدة ساعتين يوميا 10.03\% من إجمإلى عينة الدراسة ، وبلغت نسبة من يستخدم وسائل التواصل الإجتماعي لمدة ثلاث ساعات 70.60\% من إجمإلى عينة الدراسة، وبلغت نسبة من بستخدم وسائل التواصل الإجتماعي لمدة أكثر من ثلاث ساعات 1.40\% من إجمإلى عينة الدراسة. 
7. ما مجالات استخدامك لوسائل التواصل الإجتماعي؟

جدول(11)

مجالات استخدامك لوسائل التواصل الإجتماعي

\begin{tabular}{|c|c|c|}
\hline \multicolumn{2}{|c|}{ عينة البحث } & \multirow{2}{*}{ معدل الإستخدام } \\
\hline$\%$ & ك & \\
\hline 68.87 & 239 & مواقع تعليمية \\
\hline 15.20 & 53 & مواقع ترفيهية \\
\hline 15.85 & 55 & مواقع ثقافية \\
\hline 100 & 347 & الإجمالى \\
\hline
\end{tabular}

تثير النتائج التفصيلية للجدول السابق أن نسبة من يستخدم المواقع التعليمية بلغت

68.87 من إجمالِى من يستخدم وسائل التواصل الإجتماعي من عينة الدراسة ، وجاءت نسبة

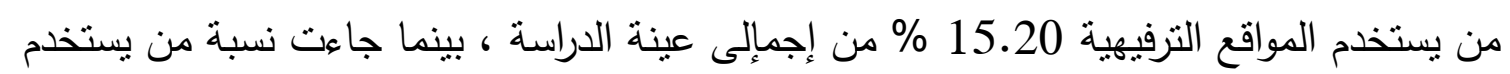
المواقع الثقافية ثلاث 15.58\% من إجمإلى عينة الدراسة . 8. ما أسباب استخدامك لوسائل التواصل الإجتماعي ؟

\section{جلول(12)}

أسباب إستخدامك لوسائل التواصل الإجتماعي

\begin{tabular}{|c|c|c|}
\hline \multicolumn{2}{|c|}{ عينة البحث } & \multirow{2}{*}{ معدل الإستخدام } \\
\hline$\%$ & ك & \\
\hline 12.96 & 45 & تساعد في الحصول على المطلومات الرياضية التي أحتاجها \\
\hline 4.32 & 15 & توفر لي كثيراً من الوقت والجهر للبحث عن التدريبات الرياضية \\
\hline 6.34 & 22 & تفيدني في معرفة طرق التريبات الرياضية \\
\hline 64.26 & 223 & تساعدني في إكتساب عادات صحية وسلوكيات رياضية سليمة \\
\hline 3.17 & 11 & تزودني بخبرات حليثة في الأداء الرياضي \\
\hline 2.88 & 10 & استخدامها غير مكلف وفي متتاول الجميع \\
\hline 3.74 & 13 & تحقق مزيداً من الإثارة والتثويق لايَ عند الإستخدام \\
\hline 2.30 & 8 & تطور من المستوى البذني لايَ \\
\hline 100 & 347 & الإجمالي \\
\hline
\end{tabular}


تثبير النتائج التقصيلية للجدول السابق أن أسباب إستخدام عينة البحث لوسائل التواصل الإجتماعي كان أكثرها "تساعدني في إكتساب عادات صحية وسلوكيات رياضية سليمة" ، بنسبة (64.26\%) ، و "تنساعد في الحصول على المعلومات الرياضية التي أحتاجها" ، بنسبة (12.96\%) ، يليها "تفيدني في معرفة طرق التنريبات الرياضية" ، بنسبة (6.43\%) ، ثم "توفر

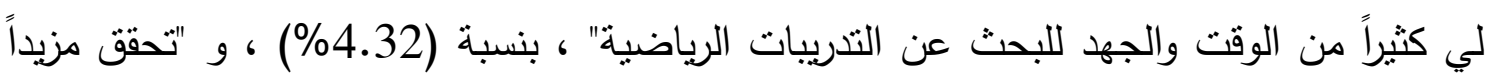
من الإثارة والتثويق لديَ عند الإستخدام" ، بنسبة (3.74\%) ، و "تزودني بخبرات حديثة في الأداء الرياضي" ، بنسبة (3.17\%) ، ثم "إستخدامها غير مكلف وفي متتاول الجميع" ، بنسبة

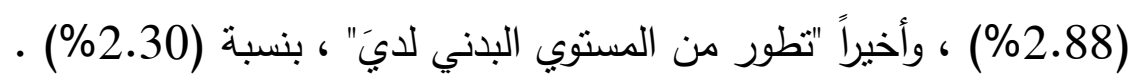
9. يؤدي استخدامك لمواقع التواصل الإجتماعي إلى تحقيق الإثباعات التالية:

\section{جدول(13)}

إثباعات استخدام مواقع التواصل الإجتماعي جلاع

\begin{tabular}{|c|c|c|}
\hline \multicolumn{2}{|c|}{ عينة البحث } & \multirow{2}{*}{ إثباعات الإستخدام } \\
\hline$\%$ & ك & \\
\hline 3.74 & 13 & شغل وقت الفراغ والتخلص من الملل \\
\hline 2.30 & 8 & تحسين مستوى الأداء البدني \\
\hline 59.65 & 207 & تكوين الخبرات اللازمة لممارسة التدريب البدنية المفيدة \\
\hline 11.52 & 40 & التعلُّم والتدريب على كثير من التدريبات البدنية \\
\hline 11.23 & 39 & التعرف علي عادات صحية سليمة \\
\hline 2.88 & 10 & جمع المعلومات عن الممارسات الرياضية الصحية \\
\hline 2.59 & 9 & الحصول على معلومات غذائية سليمة \\
\hline 3.17 & 11 & الثعور بالسعادة \\
\hline 100 & 347 & الإجمالسي \\
\hline
\end{tabular}

تثير النتائج التقصيلية للجدول السابق أن إستخدام مواقع التواصل الإجتماعي يؤدي الي تحقيق الإثباعات التالية : " تكوين الخبرات اللازمة لممارسة التشريب البدنية المفيدة" ، بنسبة (59.65\%) ، يليها " التعلُّم والتدريب على كثبر من التدريبات البدنية" بنسبة (11.52\%) ، ويليها " التعرف علي عادات صحية سليمة" (11.23.5\%) ، ثم " شغل وقت الفراغ والتخلص من الملل" بنسبة (3.74\%) ، ثم " الثعور بالسعادة" بنسبة (3.17\%) ، يليها " جمع المعلومات عن 
الممارسات الرياضية الصحية" بنسبة (2.88\%) ، ثم " تحسين مستوى المعارف الرياضية" بنسبة (2.88\%) ، ثم "الحصول على معلومات غذائية سليمة" بنسبة (2.59\%) ، وأخيراً " تحسين

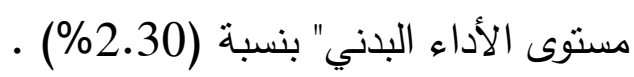
10. ما الموضوعات التي تقبل على تصفحها بوسائل التواصل الإجتماعي؟ جدول(14)

الموضوعات التي تقبل على تصفحها بوسائل التواصل الإجتماعي جلول

\begin{tabular}{|c|c|c|}
\hline \multicolumn{2}{|c|}{ عينة البحث } & \multirow{2}{*}{ الموضوع } \\
\hline$\%$ & ك & \\
\hline 3.45 & 12 & 1- الموضوعات الإخبارية. \\
\hline 10.08 & 35 & 2- 2 الأغاني . \\
\hline 12.39 & 43 & 3- الموضوعات المتصلة بتوضيح السلوكيات الصحية \\
\hline 4.89 & 17 & 4- الموضوعات الترفيهية \\
\hline 63.97 & 222 & 5- الموضوعات الرياضية \\
\hline 4.89 & 17 & 6- الموضوعات العلمية \\
\hline 100 & 347 & الإجمالسي \\
\hline
\end{tabular}

تشير النتائج التقصيلية للجدول السابق أن أكثر الموضوعات التي تقبل علي تصفحها عينة البحث بوسائل التواصل الإجتماعي جاءت بالترتيب التالي: الموضوعات الرياضية بنسبة 63.97، ثم الموضوعات المتصلة بتوضيح السلوكيات الصحية بنسبة 12.39\% ، ثم الأغاني بنسبة 10.08 \% ، ثم الموضوعات الترفيهية، و الموضوعات العلمية بنسبة 4.89 \%، ثم جاءت في المرتبة الأخيرة الموضوعات الإخبارية بنسبة 3.45\% . الإجابة على تساؤل البحث الثاني: وسائل التواصل الإجتماعى وتأثيرها على المجتمع لممارسة الرياضة كأسلوب حياة صحى باولة الكويت : - - يؤدي إستخدامك لوسائل التواصل الإجتماعي إلي التأثير علي السلوكيات التالية:

\begin{tabular}{|c|c|c|c|}
\hline \multicolumn{2}{|c|}{ عينة البحث } & \multirow{2}{*}{ 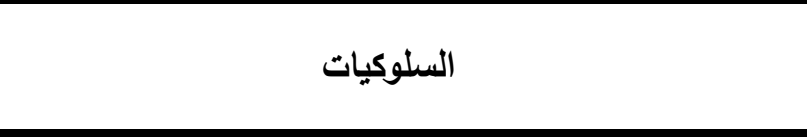 } & \multirow{2}{*}{ p } \\
\hline$\%$ & st & & \\
\hline 95 & 187 & إكتساب سلوكيات تتعلق بحب ممارسة الرياضة كإسلوب حياة & 1 \\
\hline 61.5 & 123 & إكتساب سلوكيات تتعلق بتقدير أهية ممارسة الرياضة & 2 \\
\hline 78 & 156 & إكتساب سلوكيات تتعلق بعادات صحية سليمة & 3 \\
\hline
\end{tabular}




\begin{tabular}{|c|c|c|c|}
\hline 55.5 & 111 & إكتساب سلوكيات تتعلق بالإقتداء بنماذج رياضية ناجحة & 4 \\
\hline 86.5 & 173 & إكتساب سلوكيات تتعلق اللياقة البدنية & 5 \\
\hline 71.5 & 143 & إكتساب سلوكيات تتعلق مشاركة الزملاء الممارسين للرياضة & 6 \\
\hline 89.5 & 179 & إكتساب سلوكيات تتعلق بالتغذية السليمة & 7 \\
\hline 91.5 & 183 & إكتساب سلوكيات تتعلق بحسن إستغلال وقت الفراغ & 8 \\
\hline 81 & 162 & إكتساب سلوكيات تتعلق بحب الأداء البدني بصفة يومية & 9 \\
\hline 85.5 & 171 & إكتساب سلوكيات تتعلق بالمحافظة علي الصحة العامة & 10 \\
\hline 93.5 & 190 & إكتساب سلوكيات تتعلق بالحفاظ علي صورة الجسم السليمة & 11 \\
\hline 56.5 & 113 & 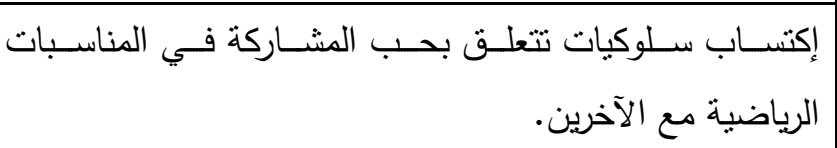 & 12 \\
\hline 45 & 90 & إكتساب سلوكيات تتعلق بالعادات الرياضية السليمة & 13 \\
\hline 69.5 & 139 & إكتساب سلوكيات تتعلق بالمحافظة علي وزن الجسم & 14 \\
\hline
\end{tabular}

تثنير النتائج التفصيلية للجدول السابق أن أكثر السلوكيات التي يمكن أن تسهم وسائل التواصل الإجتماعي في إكتسابها هي علي التوالي: "إكتساب سلوكيات تتعلق بحب الممارسة كإسلوب حياة" ، وقد جاءت بنسبة 95\% ، ثم "إكتساب سلوكيات ثتعلق بتقدير أهمية ممارسة الرياضة" بنسبة 93.5\%، وأقلها "إكتساب سلوكيات تتعلق بالعادات الرياضية السليمة" ، وبنسبة

توصل الباحث من خلال تحليل آراء عينة البحث من الطلبة والطالبات حول وسائل التواصل الإجتماعي وتأثيرها علي المجتمع لممارسة الرياضة كإسلوب حياة :

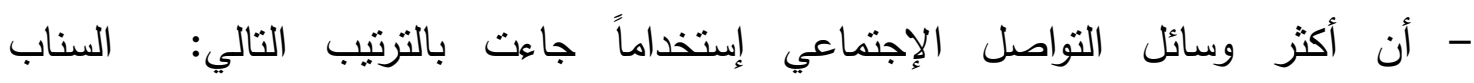
شات(Snapchat)، الفيس بوك (Face book) ، ثم موقع تويتر(Twitter) ، ثم موقع

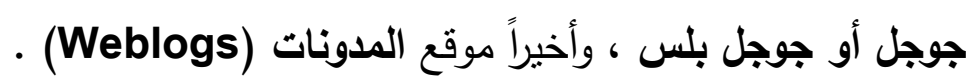
- أن أكثر السلوكيات التي يمكن أن نسهم وسائل التواصل الإجتماعي في إكتسابها هي علي التوالي: "إكتساب سلوكيات تتعلق بحب الممارسة كإسلوب حياة" ، ثم "إكتساب سلوكيات تتعلق بتقدير أهمية ممارسة الرياضة" ، وأقلها "إكنساب سلوكيات تتعلق بالعادات الرياضية السليمة". 
في ضوء النتائج التي توصل اليها الباحث يوصى مايلي: - ضرورة إستفادة المجتمع الكويتى وخاصة الثباب من وسائل التواصل الإجتماعى. - ضرورة إستخدام وسائل التواصل الإجتماعى التي تسهم في إكتساب سلوكيات رياضية مفيدة ومتعددة.

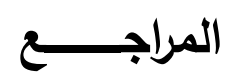

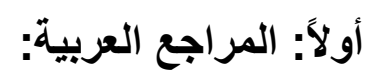

: دور شبكات التواصل الاجتماعي في تتمية مشاركة الثباب الفلسطيني في القضايا المجتمعية

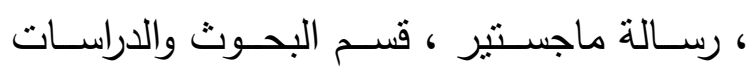

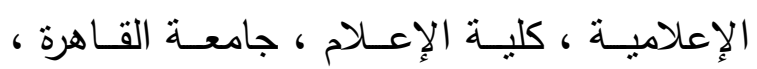
مصر .

: دور شبكات التواصل الاجتماعي في نتكيل

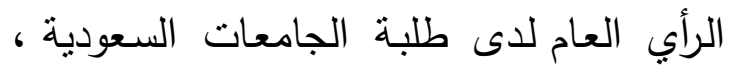

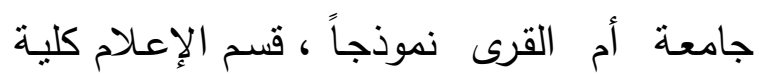
العلوم الإجتماعية ، جامعة أم القري ، السعودية. : الإعلام الجديد تطور الْداء والوسيلة والوظيفة. 1. أحمد يونس محمد حمودة (20134)
الإعلاميلة ، كلية الإعلام ، جامعة للفاهرة ،

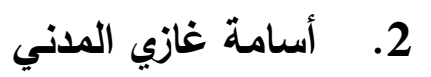 (2014)

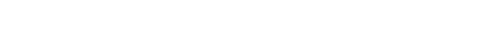


والأسـرية ، تخصص خدمـة إجتماعيـة ، جامعـة

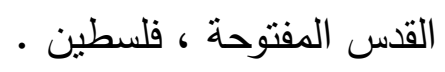

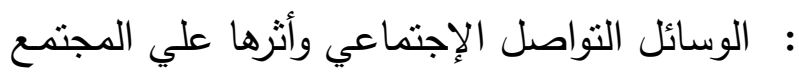

7. شكري عبد الحميد حماد

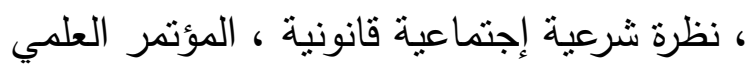

(2014)

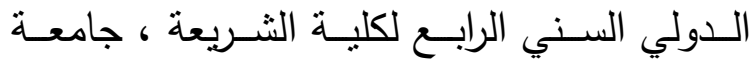

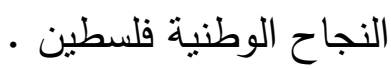

: الإعام الجديد المفاهيم والوسائل والتطبيقات،

مكتبة الثروق، القاهرة.

: والإعلام الجديد والصحافة الإلكترونية ، دار وائل

8. عباس مصطفى صادق

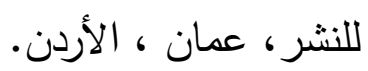

(2008)

9. عبد الرازق الدليمي

(2011)

10. عبد الله منصور (2012م) : تأثثر شبكات التواصل الاجتماعي على جمهور الادن المتلقين، دراسة مقارنة للمواقع الاجتماعية والمواقع الإكترونية" العربية أنموذجاً"، رسالة ماجستير في الإعلام والاتصال مجلس كلية الآداب والتربية، الأكاديمية العربية في الدانمارك.

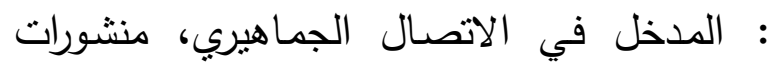

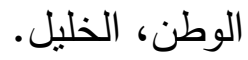

11. 11 عصام سليمان موسىى

(1994)

12. ليلى أحمد جرار (2012م) الفيسبوك والثنباب العربي ، مكتبة الفلاح للنشر

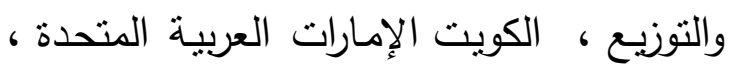

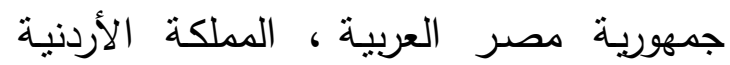

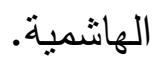

: مبادىء علم الاتصال ونظريات التأثثير ، الدار

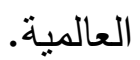

ا

13. محمود حسن إسماعيل

(2003)

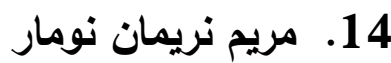

العلاقات الاجتماعية دراسة عينة من مستخدمي

(2012)

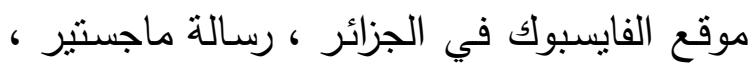

في علنوم الإعـام والإتصـال تخصص الإعـام

وتكنولوجيـا الإتصـال الحديثـة ، جامعـة النجـاح 


$$
\begin{aligned}
& \text { لخضر ، باتتة ، الجزائر. } \\
& \text { : الانترنت طريق المعلومات السربع، دط ، مطابع } \\
& \text { المكتب المصري الحديث. } \\
& \text { 15. مصطفى رضا عبد الوهاب }
\end{aligned}
$$

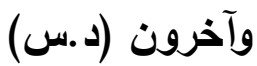

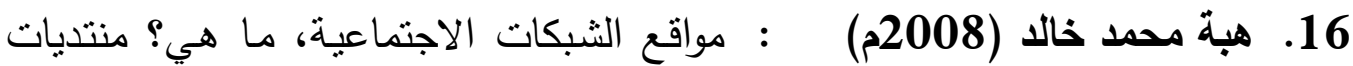

$$
\begin{aligned}
& \text { اليسار للمكتبات وتقنية المعلومات. }
\end{aligned}
$$

\section{ثانياً: المراجع الإنجليزية:}

17. Iordache, D. D. : "Exploring the Usage of Social Lamanauskas, V. Networking Websites: Perceptions and (2013) Public Opinions of Romanian University Students”. Informatica Economică; 17 (4). 